\title{
BMJ Global Health Partnership with private for-profit sector for universal health coverage in sub- Saharan Africa: opportunities and caveats
}

\author{
Juliet Nabyonga-Orem 다, ${ }^{1}$ Joy Belinda Nabukalu, ${ }^{2}$ Sam Agatre Okuonzi ${ }^{3}$
}

\begin{abstract}
To cite: Nabyonga-Orem J, Nabukalu JB, Okuonzi SA. Partnership with private forprofit sector for universal health coverage in sub-Saharan Africa: opportunities and caveats. BMJ Glob Health 2019;4:e001193. doi:10.1136/ bmjgh-2018-001193
\end{abstract}

Handling editor Seye Abimbola

Received 25 September 2018 Revised 11 February 2019 Accepted 15 February 2019

Check for updates

(C) Author(s) (or their employer(s)) 2019. Re-use permitted under CC BY-NC. No commercial re-use. See rights and permissions. Published by BMJ.

${ }^{1}$ Health systems and services cluster, WHO Inter-country support team for East and Southern Africa, Harare, Zimbabwe

${ }^{2}$ Independent consultant, HealthNet Consult, Kampala, Uganda

${ }^{3}$ Independent consultant, Elpis Consult, Kampala, Uganda

Correspondence to Dr Juliet Nabyonga-Orem; nabyongaj@who.int

\section{BACKGROUND}

Sustainable Development Goal 3: "Ensure healthy lives and promote well-being for all at all ages", with an ambitious target of attaining universal health coverage (UHC), is the aspiration of almost all countries. UHC is defined as access for the whole population to good-quality health services without the risk of financial hardship. ${ }^{1}$ Unfortunately, the public sector in most sub-Saharan African (SSA) countries lacks the capacity to provide this range of services to the whole population. Emphasis has been on strengthening the public health sector despite the resource limitations. The private sector is a potential resource for covering the gaps the public sector is unable to fill and this implores us to explore options for meaningful partnerships. The objective of this commentary is to explore the opportunities, caveats and the potential for partnership with the PFP to achieve UHC in the context of low-income countries (LICs).

The private sector comprises private for-profit (PFP) and private not-for-profit (PNFP). In this commentary, we focus only on the PFP sector. We acknowledge the broad scope of PFP activities in health however, in this commentary, we focus only on partnerships with the PFP providers for the delivery of health services. The private sector is taken by the free-market ideology to be the engine for development and progress. This has been so thoroughly preached by the World Bank and other multilateral agencies, particularly to SSA countries, that entire national socioeconomic development policies are now hinged on the belief in 'private sector led and driven' economies. ${ }^{2}$

In the 2000s, studies were done to justify a more prominent and robust private sector involvement in the health sector. For example,

\section{Summary box}

The role of the private for-profit sector (PFP) in the provision of health services is a trendy and favourite option. But the extent to which the poor can access services needs careful consideration. Among the concerns is their urban biased distribution, the quality and pricing of their services.

- The success of partnership with the private sector appears to hinge on elaborate prerequisites which include institutions, the capacity for management and the culture to collaborate.

- There is a need to build capacity for effective partnerships and employing innovation to ensure that the PFP contributes to the attainment of universal health coverage.

Konde-Lule et $a \hat{l}$ records a multicountry study of six countries (China, India, Laos, Vietnam, Uganda and Zambia). The study concluded that there was no clear advantage of greater private-sector involvement in the health sector. Despite such findings, development agencies have continued to emphasise a bigger role of the private sector in health. Many poor countries have had to adopt a 'bigger private role' policy as a condition of donor aid from agencies such as the World Bank. $^{2}$

\section{THE NATURE OF PFP SECTOR IN LICS}

The PFP sector in LICs is broadly categorised as either formal or informal. While the former includes the for-profit healthcare providers that are registered under the country's regulations and operate commercially, the latter includes those with unknown professional qualification who operate outside the formal documentation requirements. The informal private sector is heterogeneous with varying levels 
of education and training of the practitioners, as well as the contents of their practice and business models. ${ }^{4}$

\section{THE ROLE OF PFP SECTOR IN HEALTH SERVICES}

Despite the use of PFP providers by a significant part of the population, ${ }^{5}$ several concerns have been raised. Among these is the quality of services they provide, their pricing policies and the varying capacities ${ }^{6}$; the dispensation that is based on client affordability rather than dosage requirement, ${ }^{7}$ unethical practices ${ }^{8}$ and proliferation of private providers. ${ }^{9}$ Concerns notwithstanding, significant use of the PFP in LICs has been documented for specific services including institutional deliveries, primary healthcare services, and treatment for diarrhoea, fever and cough among children. ${ }^{10}$

Some studies have shown a correlation between private sector participation in management of childhood respiratory diseases and overall access to these services, with a resultant reduction in disparity in access between rich and poor, as well as urban and rural populations. ${ }^{11}$ Unfortunately, PFP participation in preventive services is minimal perhaps due to the low profit such services attract and the unwillingness of clients to make out-ofpocket (OOP) payment for preventive non-threatening health issues. Participation of PFP in diseases outbreaks is also minimal. PFP providers are acknowledged in the communities they serve as having superior public relations and display better discipline compared with the public sector. They render services at times when public health facilities are closed, on strike or on holidays and are flexible to ensure timely access.

As countries embrace the UHC concept of 'leaving no one behind', there is a need to minimise OOP payments and improve physical access. However, the significant use of the PFP coupled with the limited capacity of countries in SSA to regulate the pricing practices has accounted for high OOP and catastrophic health expenditures in many countries. ${ }^{12}{ }^{13}$ Attempts to enforce price controls have been limited and largely in the framework of health insurance schemes. ${ }^{5}$ The contribution of the PFP providers to improving physical access is limited since governments in many SSA countries lack the capacity to manage the distribution of private health facilities. ${ }^{5}$ Indeed, majority of PFP are based in urban areas and formal certification of need is not part of the licensing requirements. ${ }^{5}$

The urban biased distribution of the PFP facilities accentuates inequality in services provision. Fewer and less skilled providers, inadequate infrastructure and medical supplies, and poor diagnostic capacity characterise PFP facilities in rural areas in SSA. ${ }^{7}$ Hanson and Berman, ${ }^{14}$ however, observe that such gaps can partially be compensated by the rural-biased distribution of the PNFP providers. This may be true but the approach for ensuring such compensatory gap-reduction is yet to be ascertained.

PFP have been credited for innovation in service delivery which improves access especially for marginalised populations. The house-to-house service delivery model by private informal health service providers to deliver basic care to rural residents and deployment of diagnostic technology to improve quality of care are among the innovations. ${ }^{15}$ These have, however, been on a small scale and the cost implications to realise similar results on a national scale can be prohibitive. On the other hand, the PFP sector has been criticised for offering a narrow range of services and in most cases as a sole proprietorship with inherent limitation to quality and scope. ${ }^{16}$

\section{PUBLIC-PRIVATE PARTNERSHIP IN HEALTH}

Public-private partnership in health (PPPH) is any formal collaboration between the public sector and the non-public health sector for the delivery of health services, products, equipment, research or education. Partnerships are built to enhance and accumulate capacity and effectiveness in service delivery. Isolated efforts have limited impact because expertise and lessons learnt are neither shared nor combined. With effective collaboration, each organisation can focus on its strongest areas. By cooperating with interested parties, governments are able to provide broad-based and high-quality health services to the population. PPPH could potentially fill the gap in service provision despite the additional burden of regulating how the partnership with a for-profit entity will work to improve access. The concerns about the likelihood of a large private sector undermining the integrity of a national health system ${ }^{17}$ can easily be curtailed by good regulatory capacity. In as much as it is feasible in many SSAs, there are several complexities that need to be considered before large-scale PPPH that will bridge the gap in healthcare can be accomplished.

PPPH exist in several forms including strategic partnerships bound by a memorandum of understanding (MOU) between the different parties. Several countries use MOU for providing subsidies to private health providers. In some countries, contractual arrangements bound by a legal contract have been attempted although the capacity to negotiate and monitor contracts in LIC is weak. ${ }^{18}$ Whyle and Olivier ${ }^{19}$ reported 52 individual PPPH initiatives in Southern Africa. These initiatives represent eight distinct PPPH models, including social marketing, sectorwide approach, contracting out, voucher programmes, public-private mix approach, regulation, financing and public-private partnership. Further, the review reported a lack of evidence of PPPH with informal providers given that these providers are in most cases the first port of call for the poorest segments of the population.

\section{CAN GOVERNMENTS REGULATE THE PRIVATE SECTOR?}

One sure way the government can reign in the private sector to contain its vagaries and excesses is through regulation. However, attempts to regulate the private sector have led to mixed results partly because of the way regulation is perceived and implemented. In some cases, it has been viewed as a control measure for private 
providers to get into the market and, as such, restricted to registration and licensing with little attention paid to the behaviour of providers thereafter. ${ }^{5}$ In other cases, regulation has been viewed as a punitive measure with resultant minimal cooperation from the private providers ${ }^{8}$ while in some cases failed regulation has been attributed to lack of specialised skills among government officials. ${ }^{18}$

However, successes have been documented where governments have been innovative and have employed 'influencing', 'incentives' and 'open communication' approaches. Provision of subsidies and training programmes, participation of the private sector in policy dialogue processes and access to information are some of the innovations although some of these experiences are on a small scale, while others have not been rigorously evaluated..$^{9}$ Admittedly, regulation of the private sector is complex given the fact that the sector is heterogeneous.

Regulation of the private sector is aimed at achieving health sector objectives as opposed to attempting to regulate the operations of the private sector in totality. Other scholars highlight the 'context' and among the considerations is the country's level of development, distribution and level of resourcing of the public sector, and the level of development of the private sector itself as key considerations. The approach to private sector engagement and regulation will vary given the context implying that we are looking at multiple instruments and tailored approaches. ${ }^{10}$ This argument is also supported by McPake and Hanson who advocate for tailored policies. ${ }^{20}$

The PFP sector has the advantage of reach but must be regulated to ensure a more even distribution of PFP health facilities, and provision of good quality and affordable health service. Partnerships, when established, will require a complement of sanctions and incentives including open communication and provision of opportunities for learning and participation. In order to ensure complementarity and integration within the health system, partnerships should be implemented in the broad scope of the health sector service provision encompassing public, PFP and PNFP sector. The purpose should be to fill the gaps in public healthcare provision which the PFP if well directed could easily fill to ensure that SSA countries rapidly realise UHC.

\section{PRE-REQUISITES FOR PARTNERSHIPS}

Sunderwall and Forsberg ${ }^{21}$ argue that the concept of public-private partnership needs to be further refined and further state that partnerships have three dimensions: coexistence, competition and collaboration. Within these partnerships, the two sectors are intrinsically suspicious of each other. The public sector is always grappling with funding, efficiency and political pressures. The private sector has to meet the challenges of profitability, legal framework and personnel.

In Europe where partnerships have worked successfully, there are certain pre-requisites for meaningful $\mathrm{PPPH}^{22}$ These are functional regulatory systems, available skills to manage partnership, enough time has been given to nurture the partnership, in-built business and management functions and culture, well-defined consultations and clear channels of communications with all stakeholders. Most of these pre-requisites lack in LICs and require cultivation.

\section{IMPLICATIONS FOR POLICY AND RESEARCH}

Partnership with PFP is just one tool for health sector stewardship. It must be addressed alongside other aspects of the national health policy development and in the context of UHC. Before a policy is elaborated, there is a need to assess the feasibility for partnerships, particularly the capacity to regulate and manage partnerships. Where such a capacity is low, there is a need to deliberately adopt a policy to build it. There is a need to develop a well-researched regulatory framework. Partnership with PFP is a long-term strategy and culture, which requires long-term engagements and confidence building that will often start with a simple collaboration leading to more involved engagement. Tailored partnerships must be developed in line with the assessed situation and needs on the ground.

\section{CONCLUSION}

PFP providers are a potential resource for attaining UHC. But the success of partnership with PFP in the health sector is not guaranteed. Indeed, it appears to be driven more by idealogy and trend rather than by necessity. Where PPPH has worked, such as in Europe, there are elaborate pre-requisites in place, including the culture of such collaboration, the capacity to partner and presence of strong institutions. If carefully planned and well implemented, it could be a big resource for national health service delivery. But where the necessary requirements are not in place and it is rushed into as a quick solution, it could spell disaster for the health sector.

Contributors $\mathrm{JN}-0$ conceived the study, $\mathrm{JN}-\mathrm{O}$ led the drafting of the manuscript. $\mathrm{JN}-0, \mathrm{JBN}$ and $\mathrm{SAO}$ contributed to the drafting of the manuscript. All authors reviewed and approved the final manuscript.

Funding This study was supported by World Health Organization Africa Region office.

Competing interests None declared.

Patient consent Not required.

Provenance and peer review Not commissioned; externally peer reviewed.

Data sharing statement No additional data are available.

Open access This is an open access article distributed in accordance with the Creative Commons Attribution Non Commercial (CC BY-NC 4.0) license, which permits others to distribute, remix, adapt, build upon this work non-commercially, and license their derivative works on different terms, provided the original work is properly cited, appropriate credit is given, any changes made indicated, and the use is non-commercial. See: http://creativecommons.org/licenses/by-nc/4.0

\section{ORCID iD}

Juliet Nabyonga-Orem http://orcid.org/0000-0002-1061-8678 


\section{REFERENCES}

1. World Health Organization. The World health Report-health systems financing: the path to universal coverage. Geneva, Switzerland: World Health Organization, 2010.

2. Okuonzi SA. Learning from failed health reform in Uganda. BMJ 2004;329:1173-5.

3. Konde-Lule J, Okuonzi SA, Matsiko C, et al. The potential for the private sector to improve health264 outcomes in Uganda Mimeo Makerere Univers/ty school of public health. Uganda: Health. MUloP, 2006.

4. Gautham M, Shyamprasad KM, Singh R, Meenakshi G, Rajesh S, et al. Informal rural healthcare providers in North and south India. Health Policy Plan 2014;29 Suppl 1:i20-9.

5. Doherty J. Achieving universal health coverage in East and southern Africa: what role for for-profit providers? International Conference on Public Policy, Panel session T03P13, 2015.

6. Brugha R, Zwi A. Improving the quality of private sector delivery of public health services: challenges and strategies. Health Policy Plan 1998;13:107-20.

7. Rutebemberwa E, Pariyo G, Peterson S, et al. Utilization of public or private health care providers by febrile children after user fee removal in Uganda. Malar J 2009;8.

8. Pomeroy AM, Koblinsky M, Alva S. Who gives birth in private facilities in Asia? A look at six countries. Health Policy Plan 2014;29 Suppl 1(suppl 1):i38-47.

9. Wiysonge CS, Abdullahi LH, Ndze VN, et al. Public stewardship of private for-profit healthcare providers in low- and middle-income countries. Cochrane Database Syst Rev 2016;(8).

10. Grépin KA. Private sector an important but not dominant provider of key health services in low- and middle-income countries. Health Aff 2016;35:1214-21.

11. Yoong J, Burger N, Spreng C, et al. Private sector participation and health system performance in sub-Saharan Africa. PLoS One 2010;5:e13243.
12. Van Damme W, Van Leemput L, Por I, Damme WV, Leemput LV, et al. Out-of-pocket health expenditure and debt in poor households: evidence from Cambodia. Trop Med Int Health 2004;9:273-80.

13. Su TT, Kouyaté B, Flessa S. Catastrophic household expenditure for health care in a low-income society: a study from Nouna district, Burkina Faso. Bull World Health Organ 2006;84:21-7.

14. Hanson K, Berman P. Private health care provision in developing countries: a preliminary analysis of levels and composition. Health Policy Plan 1998;13:195-211.

15. Thurston S, Chakraborty NM, Hayes B, et al. Establishing and scaling-up clinical social franchise networks: lessons learned from Marie Stopes International and Population Services International. Global Health: Science and Practice 2015;3:180-94.

16. Konde-Lule J, Gitta SN, Lindfors A, et al. Private and public health care in rural areas of Uganda. BMC Int Health Hum Rights 2010;10.

17. Hotchkiss DR, Godha D, Do M. Expansion in the private sector provision of institutional delivery services and horizontal equity: evidence from Nepal and Bangladesh. Health Policy Plan 2014;29 Suppl 1(Suppl 1):i12-19.

18. Oxfam. Half of Lesotho health budget goes to private consortium for one hospital, 2014. Available: https://www.theguardian.com/world/ 2014/apr/07/lesotho-health-budget-private-consortium-hospital [Accessed 18 Jun 2018].

19. Whyle EB, Olivier J. Models of public-private engagement for health services delivery and financing in Southern Africa: a systematic review. Health Policy Plan 2016;31:1515-29.

20. McPake B, Hanson K. Managing the public-private mix to achieve universal health coverage. Lancet 2016;388:622-30.

21. Sunderwall J, Forsberg B. Private sector in health care deliverypotentials and challenges. Stockholm, Sweden: Karolinska Institute, 2006.

22. Nikolic A, Maikish H. Public private partnership and collaboration in the health sector: an overview with case studies from research, European experience. Washington, DC.: The World Bank, 2006. 